\title{
Drawings and Traditional Ghanaian Adinkra Symbols: Proposal Drawings of Emmanuel Ofosu Kwateng Architectural Designs
}

\author{
Francis Ankyiah* Robert Amo-Broni Daniel Ato Adubah Emmanuel Ofosu Kwateng \\ University of Education, Winneba. Art Education Department, Winneba
}

\begin{abstract}
Adinkra Symbols are multifaceted by virtue of proliferating of ideas and exploration springing up across its symbolism and philosophy. The proliferating of ideas and exploration of Adinkra symbolic motifs has to lead the symbols to be amalgamated into several disciplined in academics such as drawing. However, drawing now has liberated from the traditional sense of supporting other disciplines to a medium of expression now, for this proposal drawing studies. This study reviews recent drawings of Architectural Designs by Emmanuel Ofosu Kwateng, a 21 years of age student of the University of Education, Winneba which adopts drawing as a medium to explore the multifaceted of Adinkra symbols in his Architectural Designs. Showing Emmanuel Ofosu Kwateng experimentation of adapting Ashanti's Adinkra symbols in Architectural Designs this paper investigates how traditional Ashanti's Adinkra Symbols and its visual culture is restaged and detoured in contemporary art-space to create artworks that not only bear cultural identity but possesses qualities that define contemporary art in both drawing and Architecture. The results to this search show that the philosophy and visual studying of Ashanti Adinkra Symbol exist in hybrid nature that can be appropriate into several disciplines for multifaceted form in contemporary art since it enables the re-invention of Ashanti Adinkra symbol for rich visual culture in contemporary art practices and techniques. This appropriated version of Ashanti's Adinkra symbols in an Architectural Designs situate Emmanuel Ofosu Kwateng practices into the minimalist approach to simplicity as the symbols already exist in simple forms. The proposal drawings conferred here explain the practices of contemporary art in the $21^{\text {st }}$ century can refer to cultural philosophies and symbols to produce new visual forms of realities reflecting 21 st-century artistic development.
\end{abstract}

Keywords: Proposal drawing, Adinkra symbol, Studio practice, Architectural design, and Minimalism art.

DOI: $10.7176 / \mathrm{ADS} / 80-02$

Publication date: January $31^{\text {st }} 2020$

\section{Introduction}

The aura surrounding Adinkra symbol in relation to its ideas, concepts, philosophy and oeuvre defines its originality and its authenticity in the cultural certain of the Ashanti clan. To prove its authenticity and originality Adinkra Symbols has maintained its purity ( Owusu, 2019) by avoiding it's from alteration and appropriation for so long a time since pre-colonial era and even continue to keep its originality even in this contemporary times as some scholars are of the view that "Adinkra Symbols cannot be reproducing". As we are aware, re-invention and the copy has been part of traditional artworks since its creation even during the pre-colonial era. Adinkra Symbols cannot be exempted from the practices of restaging and re-production since its creation, as its has been inspired by nature, animals and based on human believes and ideas it was invented . The philosophy embedded in Adinkra symbols were appropriated and adapted ( Aboagyewaa-Ntiri, Campion \& Kemevor, 2018) from nature and animal's visual forms.

Within these practices and concept of appropriation the oeuvre ( Derboven, Geerts \& Grooff, 2016) of Emmanuel Ofosu Kwateng "Proposal Drawings of Architectural Designs" can be situated. Contemporary art practices and concept of appropriation deem it right for integration and connectivity of visual forms ( Mcgregor \& Ragab, 2016) believes, cultures, disciplines, concepts and ideas to create a global authenticity and originality in the contemporary world. Liberating and exploration of visual forms of Adinkra Symbols from the ideological interpretation of concepts and philosophy helps the merging of its visual forms to other disciplines visual form like Architectural Design, for broader exploration and widely accepted ideologies and practices. This is clear in the "finished-unfinished" Proposal Architectural Drawing situating between drawing, architecture and extendedly into painting like design. These practices proposition the contemporary practices of Drawing medium into Architectural practices for a wider interpretation and acceptance.

This paper reviews some independent studio drawing artworks of Emmanuel Ofosu Kwateng which adapts drawing as a medium for the exploration of Ashanti Adinkra symbols into Architectural Designs. The ideas researched in the artworks interrogate cultural symbols within contemporary studio ( Adom, Agyemang \& Owusu, 2018) drawing and look at how drawing exists in connectivity to architecture designs to transmute traditional visual forms and idioms, into contemporary art as they maintained their cultural identities in minimalist forms of art. 


\section{Proposal Drawing in Independent Studio Drawing}

Artist like Donald Judd is known to be the father of Minimalism, Richard Serra and his Tilted Arc a site-specific drawing sculpture made of Corten steel was installed at Federal Plaza in New York City and Robert Smithson, Bingham Copper Mining Pit - Utah Reclamation Project, 1973 known to be his large-scale earthworks had all presented their artistic taught in sketch before the execution of the main work. Sketch as a rough note-taking serve a remarkable place in the practicing of drawing in the artist's life. It may be a guide to the artist for a further study of whatever he wants to make in his artistic endeavor. A proposal drawing could serve as both a guide to complete a work or could at the same time serve as a finished work on its own.

Using proposal/ presentation drawing, many artists often use proposal drawings to communicate their ideas to the people who construct and install their installation artworks, including teams of workers, public art officials, and private collectors as well, to know the ideas and relationships between the work and space around the work. This may be a form of endorsement of collaboration and teamwork which limits the hands of the artist or to question the idea of genius and originality in their work presented.

In Kwateng's exploration of Adinkra symbols, it is clear to believe that the drawings are proposal drawing as in his practice he stated that "my series of drawings focus on the usage of traditional Ghanaian Adinkra symbols as a source of inspiration for Architectural designs".

Then the question is how has Adinkra symbols been used or serve in the artistic culture in Ghana? and what form has it normally take? Adinkra symbol as a well-known symbolic object in the artistic culture of Ghana has mostly been associated with the Textile industry, specifically in printing. Kwateng's approach to proposal drawing is to question us another look of Adinkra symbols by liberating it from the "Myth" of portrayal mostly in fabrics and in some cases painting and sculpting on Ghanain buildings.

Kwateng's proposal drawings as it has been said exist between a finished and unfinished proposal drawing of Architectural designs as in one part seen as a complete drawing in its self and another part seen as a sketchy and "Technically constructed" by the use of compasses and mathematical instruments, which is forbidden in the Academic drawing instructions.

Mostly proposal drawing comes along text and written instruction which explains the artist's ideas, but in Kwateng's case, it was contrary to this practice as he rather prefers to portray the Adinkra symbols directly as a medium of expression to generate his ideas and skills.

\section{Role of Culture Symbols in Architecture}

One way or the other Cultural symbolism, especially the Adinkra symbols has transformed its value into more perfect global accepted through interpretations and purposes. Cultural symbols like the Adinkra symbol are now more democratic, transparent and fusing itself into the global network system for personal interpretation which devours its originality and values for more interpretation.

Flexibility, hybridity, and connectivity are signs of cultural symbols in a contemporary sense of art. Transfiguration of Adinkra symbols from its practices of 2-dimensional effect into 3-dimensional practice by Kwatengs' proposal drawing pushes it furthermore into the animation and technological powers, which in one way or the other Kwatengs' oeuvres can be juxtapose to David Adjaye's Architectural works. Adinkra symbols have been connected to a memory-test instrument in our daily testing effect to established symbolic word pairs. To Coppens, Verkoeijen \& Rikers symbol-word pairs are used to demonstrate the generalizability of the testing effect to symbol learning (2011). The approach used by the authors proves that the testing effect can also be obtained in symbol learning (2011).

Looking at the transformative, transfiguration and connectivity of cultural symbols especially Adinkra symbols is where Banahene has explored the metaphorical meanings associated with pedagogical values of Adinkra symbols in schooling and education for pluralistic context (2018). In Banahene's educational content, he implemented varied options, strategies, and ways through which people come to learn, know, and understand their world and act within it to bring about social, cultural, economic, political and spiritual changes (2018).

Symbols have existed in several forms and play several roles in the lives of mankind but its transformation role is hard to be adopted or accepted by the culture of their origin as most culture values and believes that people always attach to it normally made them untouchable and unmovable.

In the postmodern community of this contemporary world perceive cultural symbols as a tool of development and progression by perceiving beyond and develop both philosophy and the physicality of culture into technology and social life of humanity.

In education, cultural symbols like the Adinkra symbols have been transformed into mathematical instructions. Quoted in his article "Adinkra Symbols" from Bill Babbitt, Eglash made it obvious to us how math's instructors transformed Adinkra symbols and mathematics in teaching and as a source of inspiration in the teaching and learning of logarithmic to help move between two worlds of hand-crafted tradition which is the practicing of Adinkra symbols and merging it with high-tech computation (2016).

Kwateng's piece is a way of reinterpreting culture symbols for it to be exploited and expand Adinkra 
symbols in the broadest field of art. For this is what Zhang (2019) exploited the Yin and Yang symbols to reassociate it to Architecture designs of drawings for its sustainability and development of Chinese symbols. This shows a clear move of symbolic expansion to solve the problem people have for Traditional symbolic limitations. Architecture has then been interpreted and associated with the philosophical rhyme of semiotic to show how Architecture and symbolism have been useful cultural languages and expressive support for modern environmental (Smith, K., \& Kirby, S. 2008), art design to prove its aesthetic and psychological role in human society (Chen Qi 2009 ).

Symbols define object, concept, place, and attitude of people in a philosophical sense by revealing the psychological and philosophical hidden truth in the minds of people by bringing a transformation and transitions in our minds. Thou symbols have always performed well in the abstract state of event, concepts, politics and even in proverbs. Its transition from the human taught must be physically experienced in the senses about what is clear in Kwatengs architectural building designs of Ghanaian Adinkra Symbols.

\section{Adinkra Symbols and Proposal Architectural Drawing Designs of Ofosu Kwateng's Studio Practice}

"Nature is architecture, architecture in nature so as Adinkra symbol is nature architect".

Adinkra symbols by nature represent an idea or belief, along a proverb held by the Asante's people as it emanates from the defeat of the Gyaman clan by the Ashante tribe from Ghana in the medieval period. Its captured symbolizes "power" of the Ashante's over the Gyaman clan and since then Adinkra symbol has been measured as an object of value to all humanity and experiences.

Today, Adinkra symbols which were popularly used to decorate cloth for funeral exist beyond its role and unlimited colours are also featured to raise different sentiments for different events.

Existing for centuries the traditions surrounding Adinkra have evolved. Adinkra symbols can be seen in architecture, sculptures, pottery, and even incorporated in company logos, providing a profound significance to the objects on which they are placed. Kwatengs interest in Adinkra symbols also can be a review that the symbols incorporate elements of geometry in the minimal form representing things seen in nature such as trees, ferns, and animals.

Deducing basic geometrical shapes from objects and ideas from the Ashante culture generate more concept like area, length, width, and perimeter to remind humanity the role and important cultural concepts stand out to give from Adinkra symbols.

There exists the reciprocal of Kwateng's drawings as he returns back what comes from nature by basing on the geometric shapes in Adinkra symbols to generate Architectural designs which in philosophical sense as a way of planting back to nature what belongs to it through the concept of transformation by reflection, dilation, rotation, and translation as seen in fig.2. His approach develops in us the understanding of how the concept of transformations embodies natural objects, ideas, and the world.

Shapes in Adinkra symbols have been selected, transform, twist and scaled to portray arithmetic sequences of architectural designs in Kwateng's practices by turning Ashante's Adinkra symbolic concept and believe to come with his proposal architectural drawings and their interpretations below:

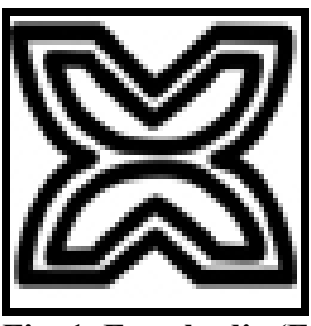

Fig. 1. Fawohudie (Freedom/ Liber

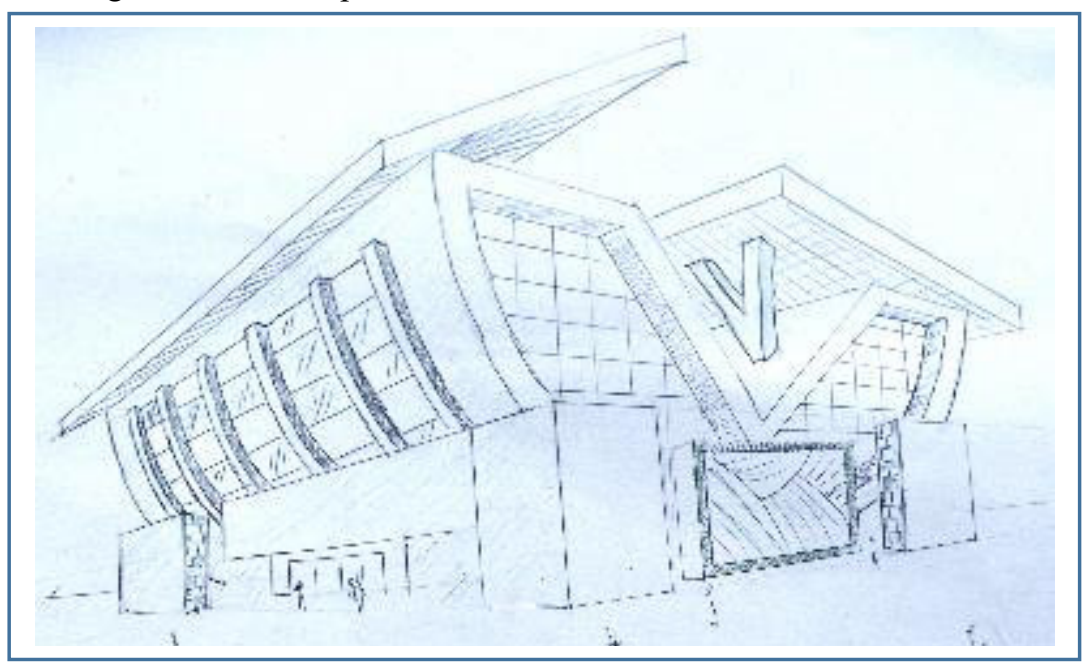

Fig. 2 Proposal Architectural Drawing designs from awohudie

Liberty is what nature and all the other elements in it have been crying and fighting to come out with cultural interpretation of subjective thinking and actions on Earth. It is within this liberty that Kwateng's proposal architectural designs seek to achieve for not restricting Adinkra symbols to only textiles application or the myths attached to it. With the half drop of the original Adinkra symbolic design been the source of 
inspiration, Kwateng's altered the original design from the two-dimensional image into three-dimensional architectural design in Lowe's sense. The illustration above (figs.1 and 2) represents the "Fawohudie" symbol and proposal architectural drawing designs from "Fawohudie" emanated from growth curves in nature. "Fawohudie" symbolizes, independence, freedom, and emancipation. From the expression: "Fawodhodie Ene Obre Na Enam", literally translated: "independence comes with its responsibilities." Freedom is normally associated with our parliamentary architectures, so looking at the architectural design of the Fawodhodie symbol in fig.2 it may be appropriate to serve as a "liberty house". In the proposal drawing (fig.2) the spiral arc dominates the upper part of the drawing to reveal the essence of peace and biological growth as peace needs to be achieved in a smooth and calm manner like the smooth flow of the spiral.

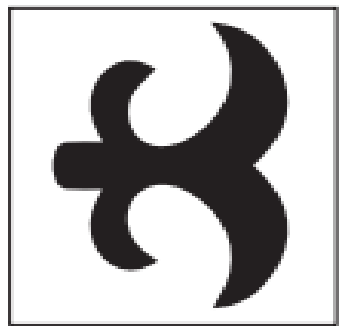

Fig. 3

Akoko Nan

(The hen Feet)

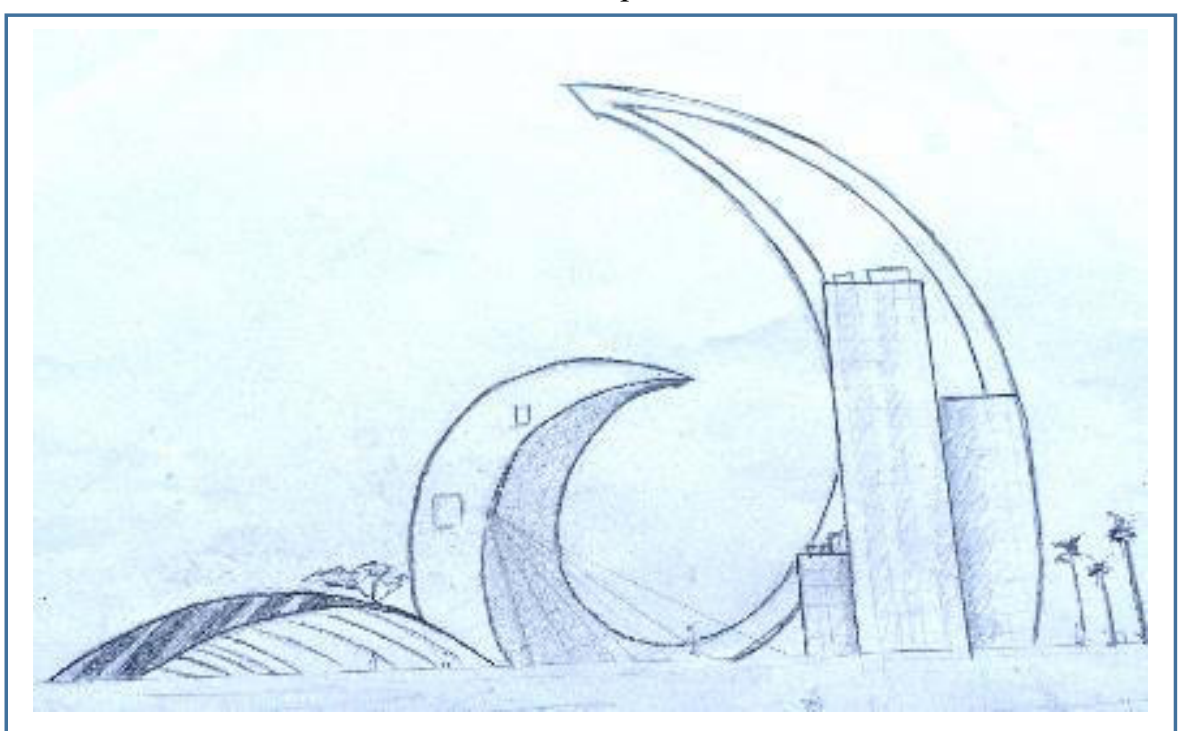

Fig. 4 Proposal Architectural Drawing designs from Akoko Nan

The figures above (fig. 3) represent the "Akoko Nan" (the hen feet) featuring a symbol of nurturing and discipline given to a child by the parents. The true symbol is translated as "The hen treads on her chicks, but she does not kill them", so with discipline shown in curves and spiral will not crack or break as planted in the Earth.

The dominant nature of spiral and geometrical curves in the proposed architectural design informs us how nature discipline mankind as motherhood is associated with the Earth in Ghanaian Akan culture in "spiral or circle". This symbols or proposal architecture design (fig. 4) represents the ideal nature of parenthood, being both protective and corrective as an exhortation to nurture children, but a warning not to pamper the younger ones too much.

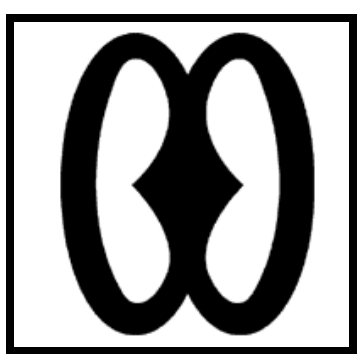

Fig. 5 Nyame Biribi Wo Soro (God, there is something in Heaven)

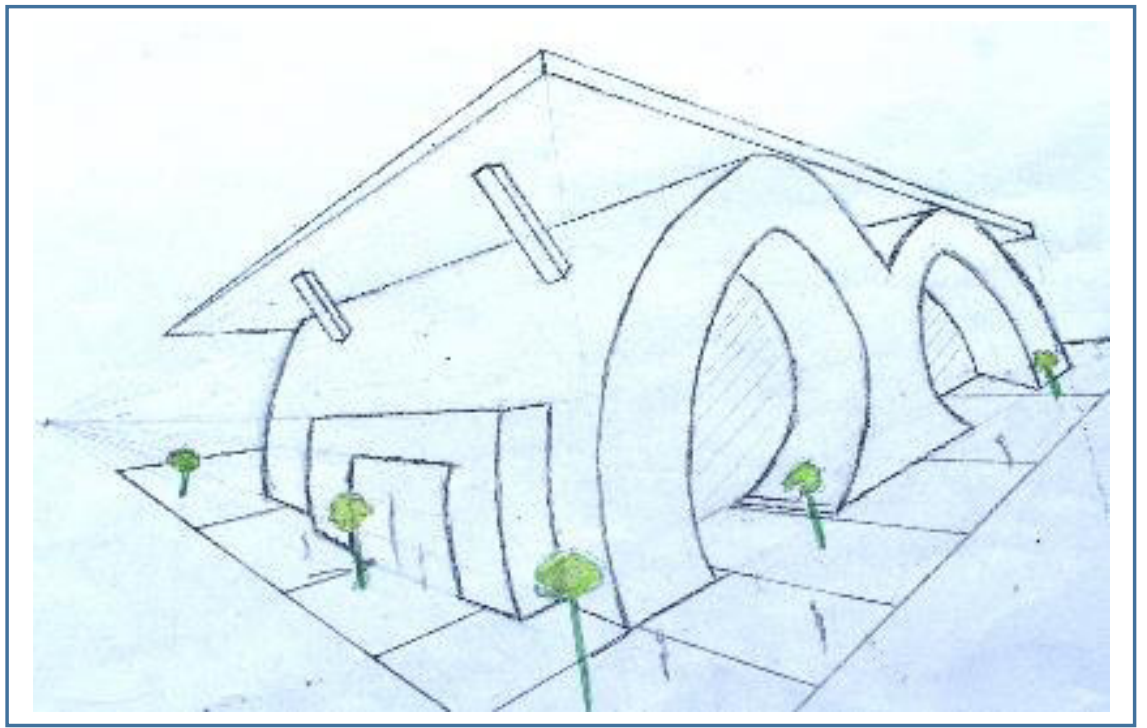

Fig. 6. Proposal Architectural Drawing Designs from Nyame Biribi Wo Soro

From the illustrations above (figs.5) represent "Nyame Biribi Wo Soro" with a repeated spiral form from the inner and outer forms of growth in nature. The symbol contains a proverbial meaning to remind us that God's dwelling place is in heaven, where he can listen to all prayers. This architectural design symbolise "hope" as it 
stands in Kwateng's work. In this proposal design (fig. 6) the concept of "half drop" is seen in the architectural design whereby the main symbol has been cut-across horizontally to generate the design. The design represents justice for all from nature and the justice it gives to us through the warmth tenderness of the spiral repetition of curves. Converting the two-dimensional shape of the symbols into 3-dimensional form for its architectural effect to serve as a justice place for all.

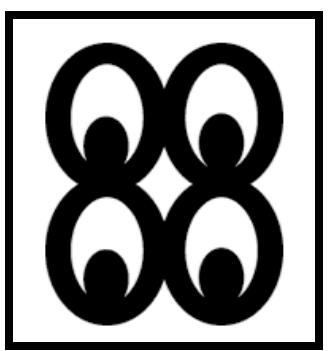

Fig. 7 Ntesie (I Have Heard and Kept It)

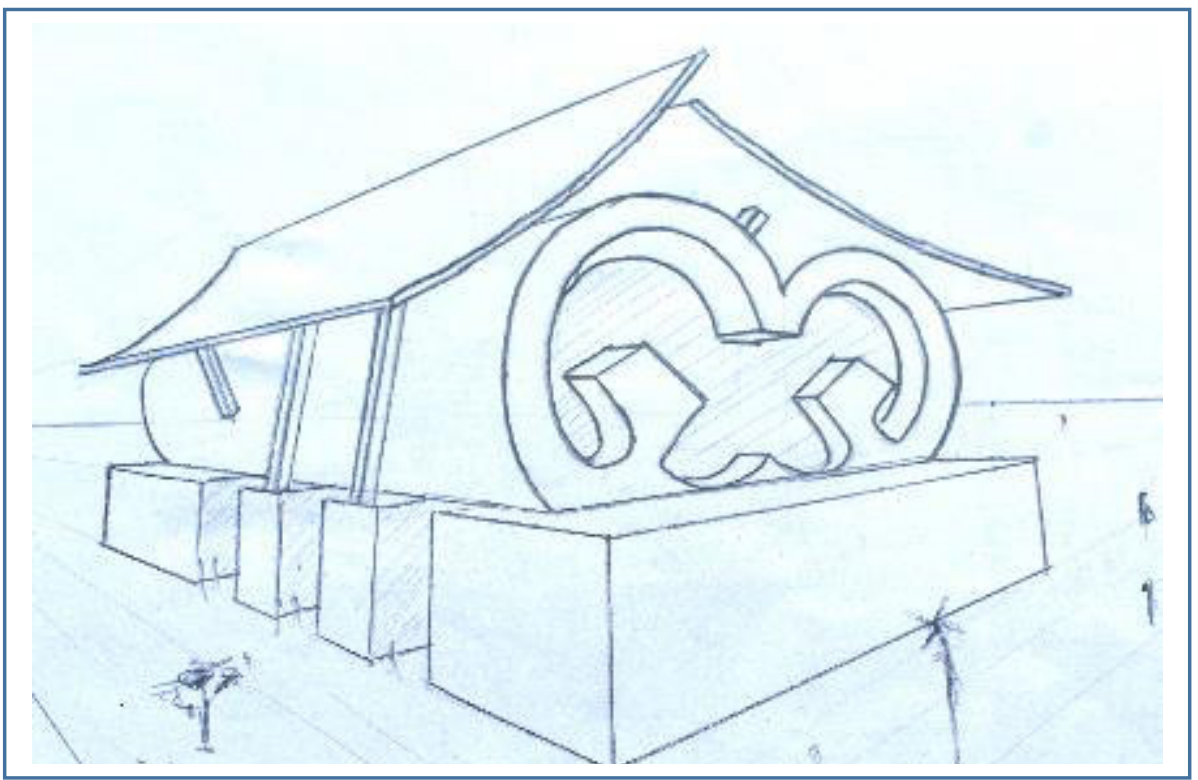

Fig. 8 Proposal Architectural Drawing Designs of Ntesie

This is the symbol called "Ntesie" (fig.7) in the Ashanti language, and translated in English as "I have heard and kept it ". The Ntesie represents the symbol of wisdom. The implied meaning of the phrase "Mate Masie" is "I understand". Understanding means wisdom and knowledge, but it also represents the prudence of taking into consideration what another person has said.

Geometric shape in the Akan symbol and language comes with its imprecation meaning and understanding of the presence of God as a supporter of the spiral shape and form of the architectural design. The drawing appears unfinished and sketchy making the drawing to exist in more representational form or proposal. The sketchy effect of the work shows the concept of growth in bits on a stable and rigid pillar of the geometrical concrete bars as one needs the wisdom to be able to endure in his or her life.

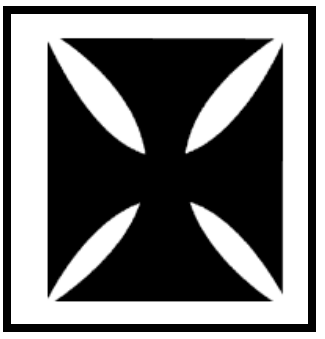

Fig. 9 Mmusuyidee "That which removes bad luck"

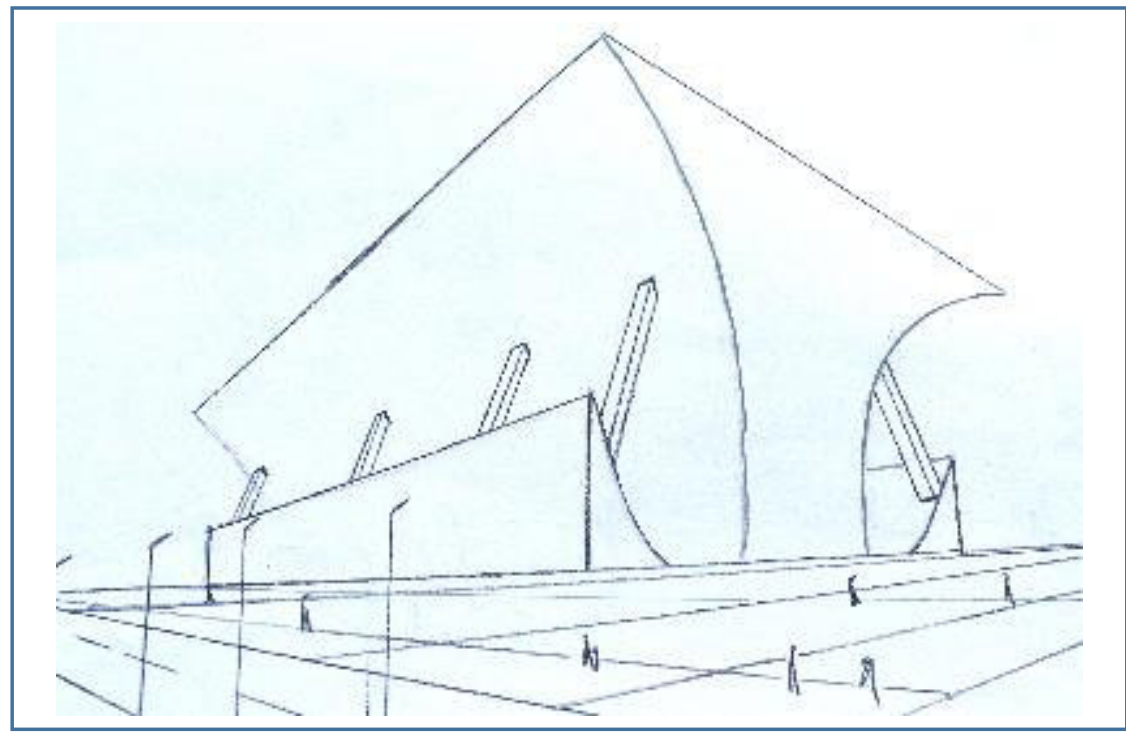

Fig. 10 Proposal Architectural Drawing Designs of Mmusuyidee

Mmusuyidee literally means "That which removes bad luck", a symbol that represents good fortune and sanctity. Looking at the architectural design good fortune can be achieved from different angles and positions seen from the movement of repeated curves and attach with vertical lines. 


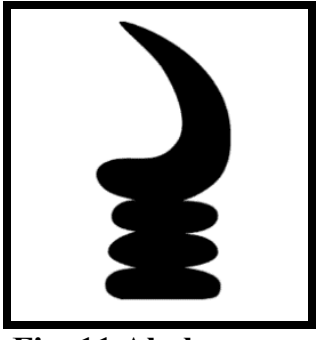

Fig. 11 Akoben (War Horn)

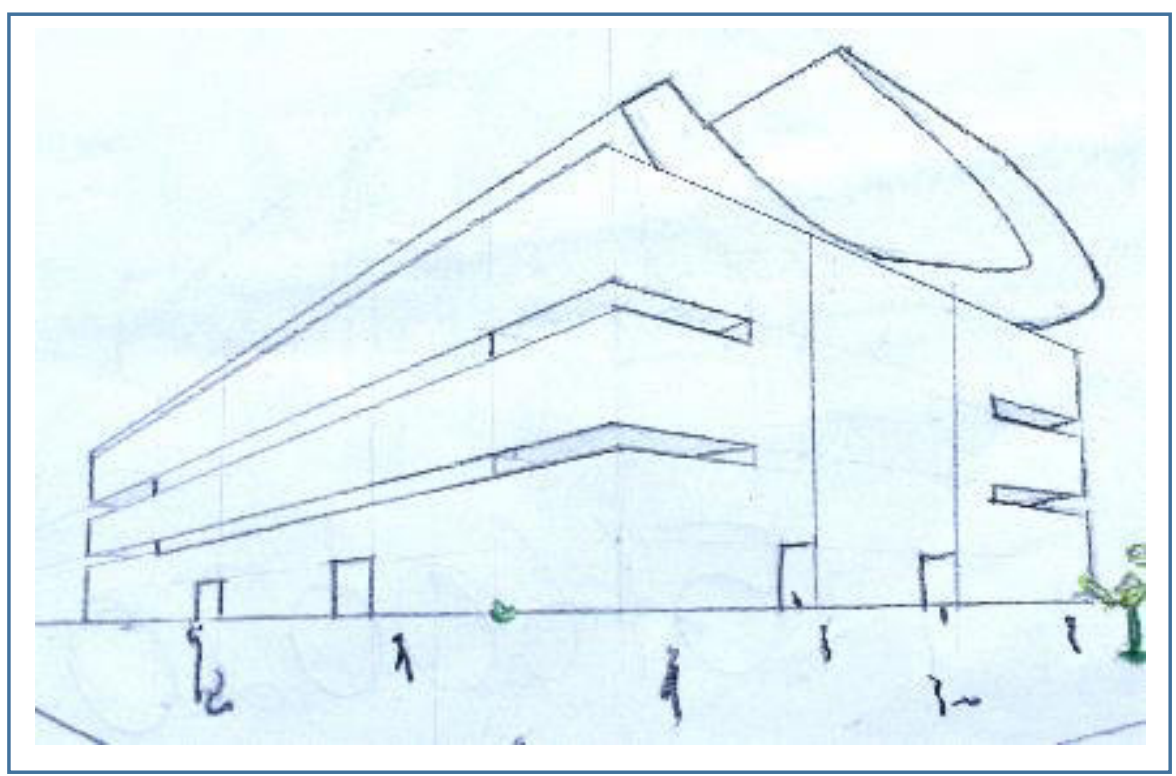

Fig. 12. Proposal Architectural Drawing Designs of Akoben (War Horn)

Problems in life are share mostly in our enclosed areas like our rooms which serve as a place of solo and joy. Like we go through a war in our rooms and a place of peace. Akoben (War Horn) a symbol for war stand out for its understanding as architectural design for and vigilance and wariness in life to do a way of life complexity of things to stick to minimal or simplicity in life. Thou geometrical shapes of squares and its vertexes give an idea of life complexity, but superimposing semi-spiral shape on it gives it fluidity and movement into the future for growth and earthiness in its vulnerable state.

Akoben is a horn used to sound a battle cry for alertness which metaphorically stands to caution us the war avail for as in life. The proposal drawing will effectively function as the architectural designs serve functions like churches or prison to serve as a sign of preparedness to war in life.

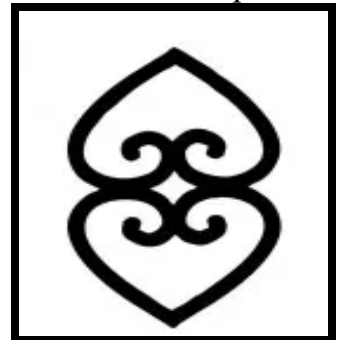

Fig. 13

Asaase Ye Duru (All

Power Manate from the Earth)

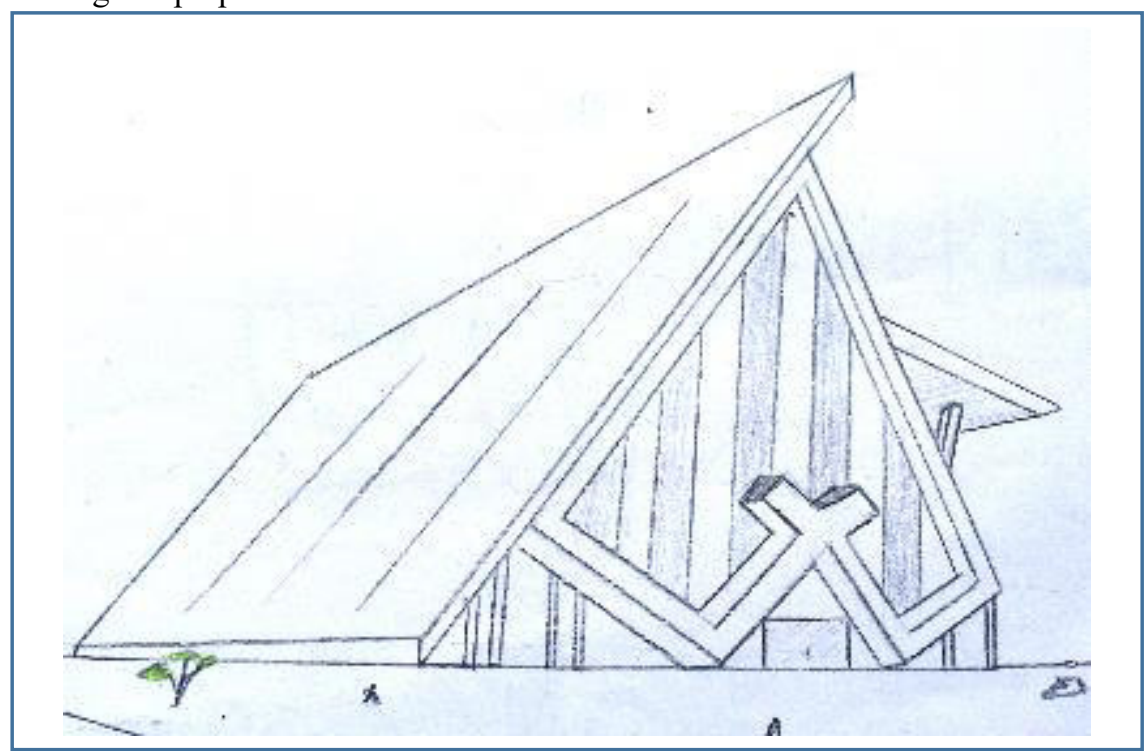

Fig. 14 Proposal Architectural Drawing Designs of Asaase Ye Duru

It is natural that all power originates from the earth so the invention and the aspirations of the Adinkra symbols originate from nature. "Asaase Ye Duru" means that " all power manate from the earth". Asaase Ye Duru can also be interpreted in English as " the Earth has weight" which is a symbol of providence and the divinity of Mother Earth. Scientifically the symbol and its meaning can be associated with "Gravitational Force" and its effect on the earth. These symbols also associated with the importance of the Earth in sustaining life and divinity.

In the proposal drawing the spiral shape of the original symbol has been altered to come out with a two V's forms intersecting into each other as the fluidity in the curve-shaped symbol in fluid in motion and can take any form it likes. In totality, the proposal architectural drawing reveals the weight that the Earth exerts on objects 
existing on it. Beneath the two flat cubic forms attaching each side to define the building in the two cross beams supporting the building to show the loving tenderness of Mother Earth.

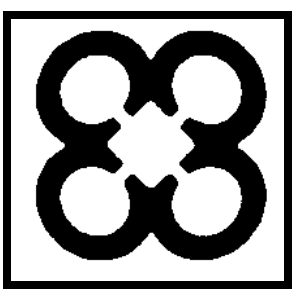

Fig. 15 Agyinduwura (Faithfulness)

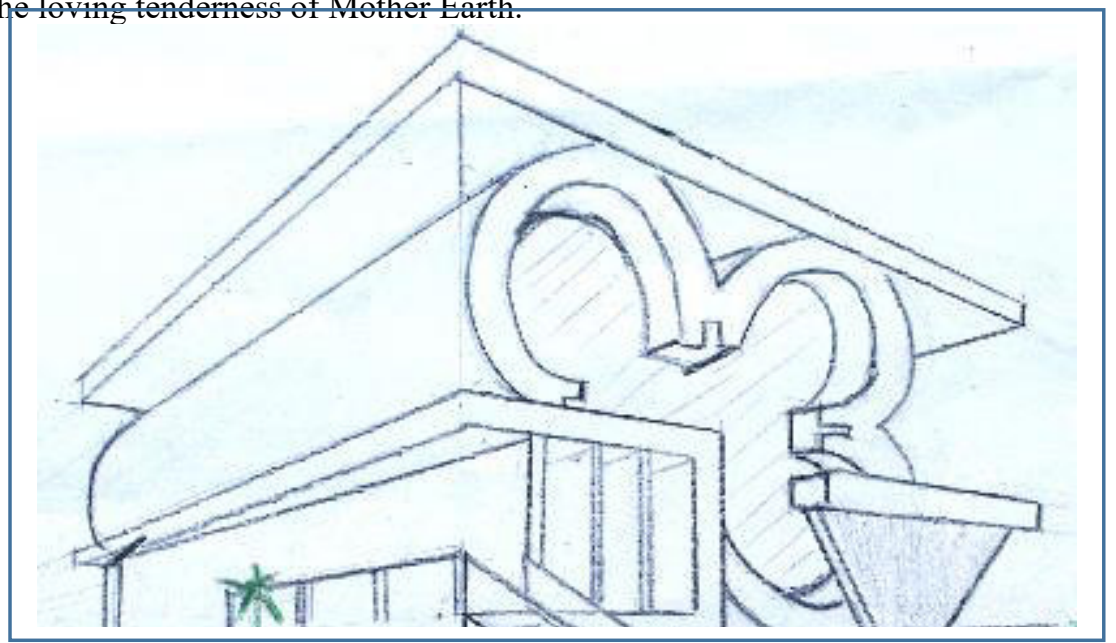

Fig. 16 Proposal Architectural Drawing Designs of Agyinduwura

The Earth supports human in all our duties in the construction of buildings, farms, roads, and industries. We have faith in the Earth and all the things it supplies us as humans. Artist depends on the wonders of the land to support their daily needs and creativity. "Agyinduwura" in Akan dialect means "Loyalty" as it is also a symbol for human loyalty to the Mother Earth. In the Akan culture the Earth is believed to be a woman, specifically means the loving mother who supports creation with a loving-kindness.

The proposal drawing for the "Agyinduwura" architecture has been represented by the repetition of four circles that define the "Agyinduwura" which means the total kindness of mother Earth for Ghanaians. the proposal drawing from the "Agyinduwura's" symbols represents a monumental building with its importance of showing the faith and kindness of the Earth in a spiral form.

\section{Proposal Drawing and Minimal Art}

Adinkra architectural design in its simplicity association of minimalism principles and concept gives the idea of sketch and essay writing or note-making. The sketch or note-taking lay the foundation for any other building or form to build on, through repetition of the same simplistic forms to generate simplistic three-dimensional designs. Minimalism or minimalistic drawing has always served to support paintings, sculptures and installation art to give direction to the curator. In Kwateng's proposal drawings, simplified Adinkra symbols were converted into three-dimensional forms by extending the two dimensional plane of Ghanaian Adinkra symbols into the distance to give it depth and repeated some parts of the original drawings of Adinkra symbols.

Proposal drawings mostly function as support to a completed work to be achieved, but at times suffer for their survival. At times too proposal drawings have been in completion before installation as an artist like Richard Serra inverts this process in his drawing "Tilted Arc", a drawing completed after his large site-specific sculpture made out of Corten steel was installed at Federal Plaza in New York City. Drawing is a significant part of Serra's artistic practice, so as another minimalist.

In the minimalist approach and practices of artwork, the fact was given to the viewers but not symbols. This idea leads one in experiencing these architectural drawing out of emotions of the symbols associated with the traditional level on the accounts of presenting fact as the practicing of "detournement" as in the contemporary sense of deconstruction of traditional elements.

Before the emergence of minimalist in the art world the same fact was provided for viewers in art but in a mysterious way as fact presented and seen in the traditional symbols were presented and preserved in a mysterious manner and form. In Kwateng's proposal, architectural designs can also be seen as displacing the mysterious presentation of traditional symbols from its mythic presentation to the proposal drawing of Architecture.

There is also thought of disenfranchising of mysterious thought in traditional artifact to the mysterious truth of proposal architectural drawings.

Furthermore, in these proposal Architectural drawings, one may experience oppositional move from a minimalist approach, as instead traditional elements have been pushed into the industrial territory of the minimalist materials. Then also in a conventional practice of the minimalist as Kwateng's practice is seen clearly to question the reevaluation of traditional values we attach to traditional symbols.

Thou one may argue that the Adinkra symbols already exist as simple and better than Kwateng's proposal Drawing as it misleads the concept of minimalist. Looking at Kwateng's drawings, still one may experience the 
original symbols of Adinkra symbols but with only a twist or extension of the symbols by giving it depth and modifications.

In the metaphorical interpretation of Kwateng's proposal, architectural designs play more centrally to the monumental presentation of sculpture piece and its feminist interpretation given to Earthy interpretation of the symbols on the proposal Architectural drawings which are different from the minimalist phallic presentation of their artworks.

\section{Conclusion}

Practicing drawing as a medium in the contemporary art education curriculum has been contributed to the expanded field of drawing by making it theoretical, experimental and ensuring an interdisciplinary method in artmaking. In doing this students are made to explore with their environment, banal objects, culture and even to question traditional and modern ideologies and practices that have already established itself and taken over all our lives and knowledge.

Independent studio practice in drawing at the University of Education, Winneba provides this contemporary freedom to student exploration in materials, events, and ideas which is not restrained students to create a finished and independent object, as in traditional painting and sculpture.

This curriculum approach has provided freedom to students like Emmanuel Ofosu Kwateng to position his drawing practice to the interdisciplinary method for merging symbolic drawings of Adinkra to contemporary architecture designs to come out with a proposal drawing, then also associated the drawings and the practices with Minimal art.

\section{References}

Aboagyewaa-Ntiri, J., Campion, B. C. \& Kemevor, A. K. (2018). Extension of Knowledge on Ghanaian Adinkra Symbols in Relation to Maslow's Theory. International Journal of African Society Culture \& Tradition.

Adinkrahene.(2019). Adinkra Symbols and Meanings: West African Adinkra Symbol of Knowledge.

Adjei, Paul. (2018). "Adinkra Symbolism of Ghana: Pedagogical Implications for Schooling and Education”.

Adom, D., Agyemang, O., Owusu, M. G. (2018). Ghanaian Cultural Symbols as Wall Decorations for Cultural Education and Revitalization in Higher Institutions of Ghana: The Case of K. N.U.S.T. Chulalongkorn.

Anne, Q. (2018). Drawing is the best way to learn, even if you're no Leonardo da Vinci.

Beyer, C. (2019). Geometric Shapes and Their Symbolic Meanings : Forms ranging from circles to dodekagrams have significance in many philosophies.

BABBITT, William et al. Adinkra Mathematics: A study of Ethnocomputing in Ghana. Multidisciplinary Journal of Educational Research, [S.1.], v. 5, n. 2, p. 110-135, june 2015. ISSN 2014-2862. Available at: $<$ http://hipatiapress.com/hpjournals/index.php/remie/article/view/1399/1212>. Date accessed: 03 oct. 2019. doi:http://dx.doi.org/10.17583/remie.2015.1399.

Coppens, L., Verkoeijen, P. J. L. \& Rikers, M. J. P. (2011). 'Learning Adinkra symbols: The effect of testing', Journal of Cognitive Psychology, 23: 3, 351 - 357, First published on: 18 March 2011 (iFirst).... DOI: $10.1080 / 20445911.2011 .507188$

Lowe, G. D. Three-Dimensional Object Recognition from Single Two-Dimensional Images.

Derboven, J. Geerts, D. Grooff, D. D. (2016). The Tactic of Everyday Practice: A Semiotic Approach to Appropriation. Interaction Design and Architecture(s) Journal.

Smith, K., \& Kirby, S. (2008). Cultural evolution: implications for understanding the human language faculty and its evolution. Philosophical transactions of the Royal Society of London. Series B, Biological sciences, 363(1509), 3591-3603. doi:10.1098/rstb.2008.0145

Mcgregor, E. \& Ragab, N. (2016). The Role of Culture and the Arts in the Integration of Refugees and Migrants. European Expert Network on Culture and Audiovisual (EENCA).

Owusu, P. (2019). Adinkra Symbols as "Multivocal" Pedagogical/Socialization Tool.Contemporary Journal of African Studies; 6 (1): 46-58 https://dx.doi.org/10.4314/contjas.v6i1.3.

Zhan, D. (2018). Cultural Symbols in Chinese Architecture. Architecture and Design Review (2018) Volume 1 doi:10.24294/adr. v1i1.211.

https://www.masud-olufani.com/conceptual-drawings-and-project proposals

http://char.txa.cornell.edu/language/element/form/form.htm

https:/www.africawithin.com/tour/ghana/adinkra.htm 